\title{
AN EX VIVO METHOD FOR THE EVALUATION OF BIOMATERIALS IN CONTACT WITH BLOOD *
}

\author{
Jerome S. Schultz, $\uparrow$ Joe D. Goddard, $\dagger$ Arthur Ciarkowski, $\dagger$ \\ John A. Penner, $\ddagger$ and S. Martin Lindenauer § \\ $\dagger$ Department of Chemical Engineering \\ $\ddagger$ Department of Internal Medicine \\ $\S$ Department of Surgery \\ University of Michigan \\ Ann Arbor, Michigan 48104
}

The use of extracoporeal (ex vivo) shunts for studying thrombus formation was given impetus by a number of studies from J. F. Mustard's laboratory. ${ }^{1,2}$ In these studies the essential problems of this method were recognized and the requirements for a reproducible system were delineated. The basic features are: 1) uniform blood flow, 2) a chamber that represents preferential region for thrombus formation, and 3) access to the thrombus for analysis. Murphy et al. ${ }^{1}$ tried a number of flow chamber designs and finally settled on the use of a model bifurcation for their studies, ${ }^{2}$ and other investigators ${ }^{3,4}$ have evaluated alternative flow chamber configurations. This type of ex vivo test with recirculation of blood should be distinguished from other ex vivo procedures in which animals are bled through a test chamber. ${ }^{5,}{ }^{\circ}$ In the latter cases chronic shunts are not used, which simplifies the procedure, but the loss of blood usually limits the duration of the experiment to less than one hour.

To develop an ex vivo method for the evaluation of the thrombogenicity of materials in contact with blood, a system was devised that exposes a test chamber to a dog's systemic circulation by means of a chronic arteriovenous shunt. The general aspects of this approach are shown in the flow diagram in Figure 1 and the schematic Figure 2.

Male dogs were selected after screening to ensure that they were normal with respect to weight and blood coagulation values. An arteriovenous shunt was implanted in accepted animals, and after surgery, coagulation factors and other physiological parameters were evaluated periodically to monitor the approach of the dog's coagulation system toward steady state. After about one week, labeled fibrinogen and platelets were introduced systemically, and after 24-48 hours the chamber containing the test material was introduced into the bypass system. The rate of thrombus formation was determined by monitoring the buildup of radioactive fibrinogen and platelets in the test chamber. Blood flow through the chamber was measured with an electromagnetic or Doppler flow meter and controlled at a constant value.

After a predetermined time the chamber was disconnected from the shunt, and any thrombus formed was removed and quantitated in terms of clot weight, moisture, fibrinogen, red cell, and platelet content. These values are used as indices of thrombus formation on a given biomaterial under defined flow conditions.

* Supported in part by the National Heart and Lung Institute, Contract No. 1HB-4-2962, and a Research Career Development Award (to J. S. Schultz) from NIGMS no. 1KO46MO8271. 


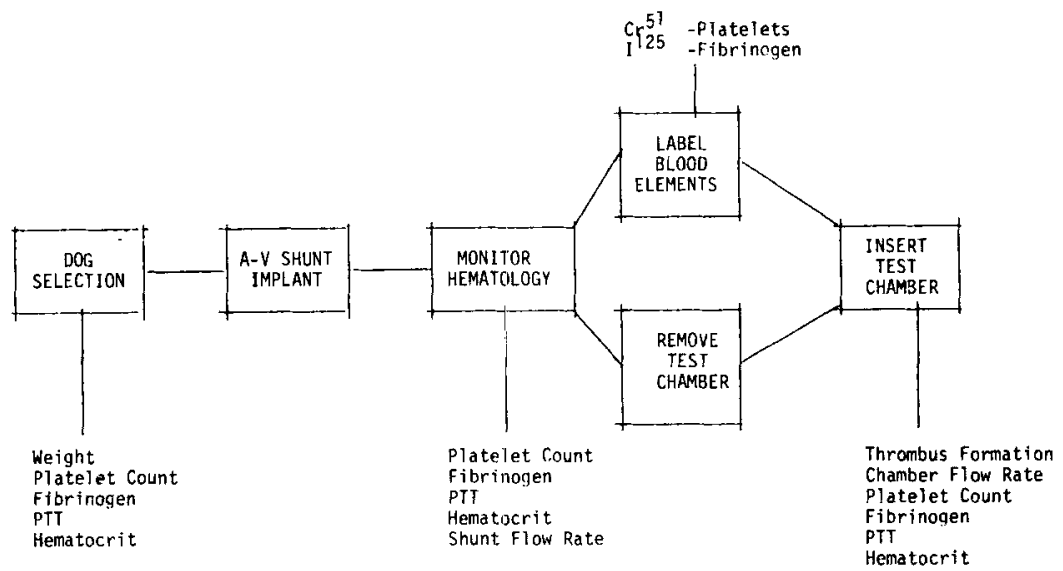

FIGURE 1. Schematic stages in biomaterials testing.

During exposure of the biomaterial to blood in the test chamber and subsequent to its removal, blood samples were taken and examined for possible systemic effects, as indicated by variations in hematocrit, fibrinogen, platelets, and other coagulation indices. The recovery of the animal from exposure to the test material was evaluated, and after a sufficient period of time, usually one week, the animal was used again in a similar study.

\section{Ex vivo SHuNT}

Chronic intermittent access to the vascular system is difficult to maintain because of several problems. Use of the venous circulation exclusively is un-

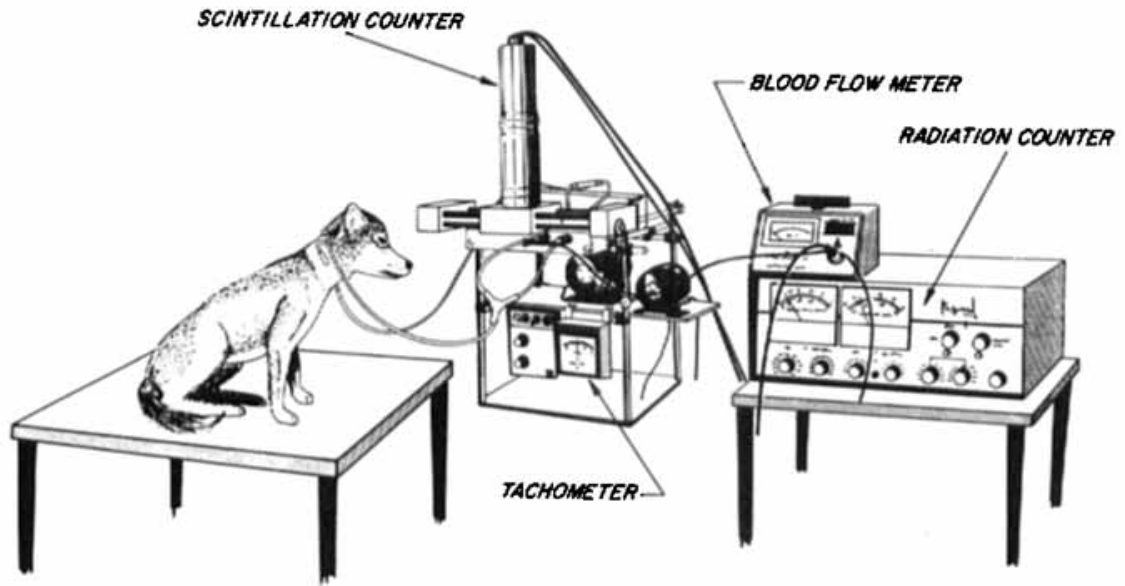

Figure 2. Components used in biomaterials testing by means of ex vivo arteriovenous shunts in dogs. 
satisfactory because the venous flow rates are too low to prevent thrombosis. Although increased flow may be achieved in an exclusively intraarterial shunt, similar problems of thrombus formation are encountered. But in the case of an arteriovenous shunt, the capillary bed is bypassed and the blood is returned to the venous circulation with essentially no peripheral resistance, so that the volumetric blood flow is very large and may equal or exceed the normal total cardiac output. Although flow rates of such magnitude seem to inhibit thrombus formation in the access device, it is nevertheless essential that the shunt surface have compatibility with blood. One such material that is compatible and highly effective in maintaining shunt patency is Silastic $\dagger$ tubing, coated internally with a heparin complex. $\ddagger$

In these experiments for the testing of biomaterials and study of the dynamics of thrombogenesis, the ex vivo arteriovenous shunt is surgically implanted in the neck, and when in place bridges the carotid artery and internal jugular vein. Two pieces of Silastic tubing (I.D. $3 / 16$ inches and about 10 inches long) are sutured to the respective vessels, and their ex vivo ends tunneled through the neck subcutaneously and dorsally so as to emerge 1.5 or $2 \mathrm{~cm}$ dorsal to the vessel-tubing anatomosis. Thus the carotid branch meets the jugular branch on the dorsal aspect of the dog's neck, a few centimeters caudal to the ears; here they are joined to form the shunt by a Teflon ${ }^{\circledR}$ stent ( $3 / 16$ inches I.D., $1 / 4$ inches O.D., 1.25 inches long). Between experiments the ex vivo portion of the shunt is wrapped in soft gauze for protection.

In order to obviate the problem of proliferation of intima at the junction of the vessel and the tubing, a process which gradually narrows the lumen and restricts flow, a porous prosthetic material is bonded to the end of the Silastic tubing, as illustrated in Figure 3. The material, Dacron ${ }^{\circledR}$ velour, constitutes about a $2-\mathrm{cm}$ extension on the end of the Silastic tube, and the jugular vein anastomosis joins to this porous material. The arrangement for the artery is similar, except that because of the disparity between the smaller diameter of the carotid and the Silastic, it is necessary to interpose between the artery and the Dacron a $1.5-\mathrm{cm}$ segment of autogenous jugular vein. Closure of the anastomoses is done with 5-0 cardiovascular suture in continuous fashion. Although standard surgical techniques are employed, extraordinary care must be exercised: in securing vessel-to-tubing junctions; in the stereoscopic placement of the shunt to avoid kinking with the movements of the head and neck in the recovered animal; and in adherence to scrupulous sterile technique to minimize risk of infection.

Emerging from the subcutaneous tunnel, the prosthesis crosses the cutaneous epithelial surface and can become a conduit for infection through the break in the skin. To combat this possibility, a sleeve of polyester felt ( $1 / 8$ inch thick) is bonded around the Silastic, starting from the Dacron velour and extending about $10 \mathrm{~cm}$, so that in the final placement, two or three centimeters of the felt-sleeved Silastic tube protrude beyond the skin surface. In the healing process, the soft tissue becomes densely adherent to the polyester, with excellent incorporation; a reliable seal is formed between the soft tissues and the shunt, effectively preventing ingress of bacteria from the skin surface.

The incisions are closed with subcuticular absorbable suture following closure of the muscle and fascia over the vascular anastomoses. For prophy-

$\dagger$ Dow Corning Medical Grade Silastic Tubing.

$\ddagger$ Battelle Laboratories, TDMAC Process. 


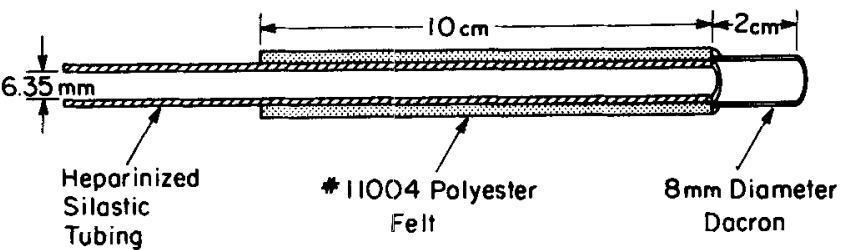

Figure 3a. Construction details of the arteriovenous shunt prosthesis; two are used in a complete shunt. Blood vessels are anatomosed to the Dacron velour.

laxis, kanomycin is administered for several days both intramuscularly and as an irrigant in the wound. No adverse cardiovascular effects were noted due to the shunt for periods of up to two months. Occasional shunt failures were attributed to kinking and/or infection. Usually, however, the dogs recovered with wounds healed sufficiently to permit postoperative testing within one week. Repeated access to the circulatory system for materials testing was easily accomplished, and volume flow rates in the range of $500-1000 \mathrm{ml} / \mathrm{min}$ were regularly obtained.

Dogs selected for these studies were preconditioned males of an average weight of $30.4 \pm 6.4 \mathrm{~kg}$. The hematological profile was as follows: platelets $309 \pm 95 \times 10^{3}\left(\right.$ per $\left.\mathrm{mm}^{3}\right)$, fibrinogen $276 \pm 101(\mathrm{mg} / 100 \mathrm{ml})$, hematocrit $44 \pm 4.4 \%$, PTT $25.7 \pm 7.3$ ( sec). The platelet and fibrinogen levels were depressed somewhat (about 30\%) after surgical implantation of the shunt, but the levels returned to normal after a one-week recovery period.

Platelet survival studies with a modified Frasher preparation ${ }^{7}$ indicated a much faster turnover rate than in normal animals; compare the solid line in FIgure 4 with the normal values shown as the dashed line. It should be noted

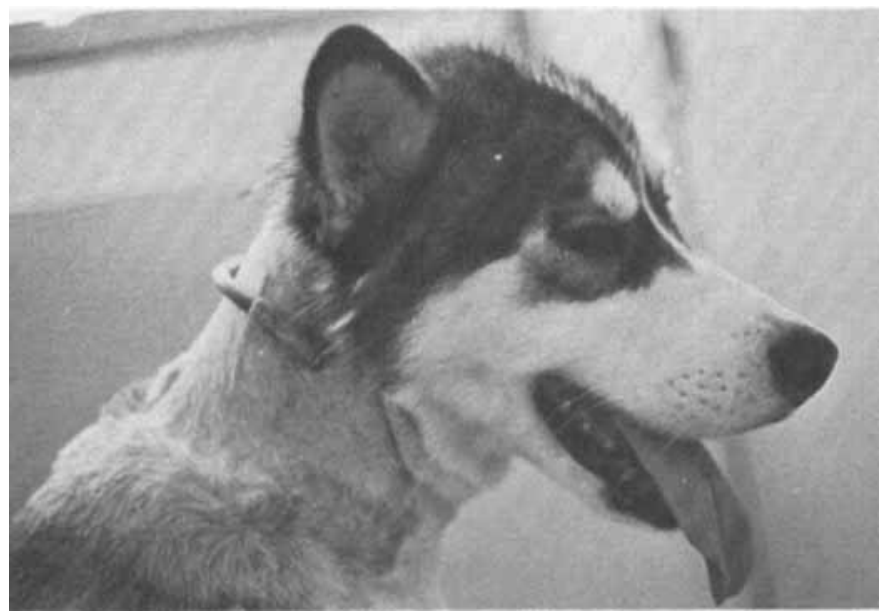

FIGURE 3b. Arteriovenous shunt in place between carotid artery and jugular vein. 
that in these experiments the test chamber was inserted in the neck shunt for about three hours on the first day, and may have accounted for some of the acceleration in platelet turnover. However, the general pattern in FiguRe 4 of selective platelet consumption along with normal fibrinogen turnover is typical of Silastic arteriovenous cannulae as described by Harker. ${ }^{8}$

\section{Test Chamber Design}

In designing the test chamber several factors were given primary consideration.

1. A well-defined flow pattern was desired to allow for future analysis of the effects of flow on various rate phenomena, such as shear rate and diffusion rates.

2. Accessibility of the thrombogenic surface to measuring techniques was desired, along with the possibility of using a variety of methods, particularly radioisotopic methods, for evaluating the rate of thrombus formation.

3. Since there are a number of schools of thought as to which of these factors play the most significant role in the development of thrombi, 9,10 a configuration that allows the separation of the effects of shear and convective mass transport is desirable. The separation or independent variation of these parameters allows the determination of the more important causative factors in thrombus development.

Based on these criteria a test chamber of the couette type was selected for the evaluation of materials in contact with blood. There is much background information available on couette-type flow geometries, and, in addition, some recent studies on platelet diffusion and platelet adsorption to surfaces have been carried out using this general configuration. ${ }^{11,12}$

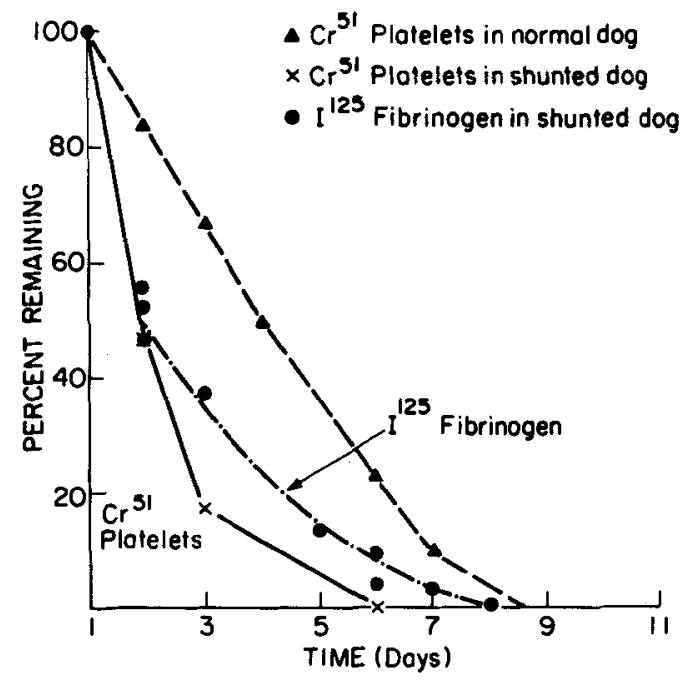

FIGURE 4. Turnover rates of labeled fibrinogen in shunted and labeled platelets in shunted and control dogs. 


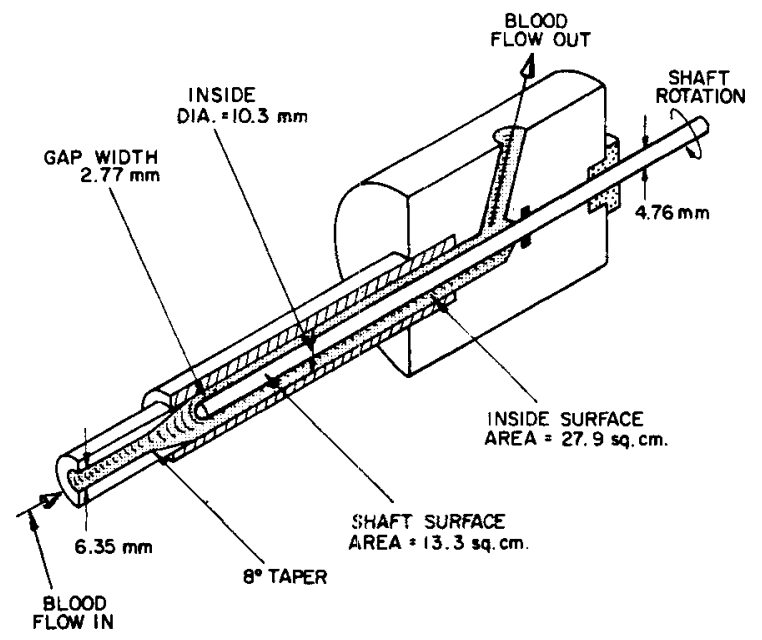

Figure 5. Biomaterials test prosthesis used in ex vivo arteriovenous shunt in dogs.

FIgURE 5 shows the configuration of the current prototype test chamber. Blood enters the chamber from the left through an expansion section and then flows down the chamber in a somewhat helical pattern to the exit port at the right, which comes off at approximately a $45^{\circ}$ angle. The test material can be coated onto the surface of the central shaft (usually 303 stainless steel) and also onto the interior surface of the cylindrical shell.

Most of the ex vivo work was done with a chamber having a central shaft of $3 / 10$ in diameter and an outer cylinder of $13 / 32$ in internal diameter. The length of the chamber is approximately 4 inches. The inlet and exit ports are approximately $1 / 4$ in I.D. The chamber presents an expansion in cross section from the inlet to the central region, and the effective (hydraulic) Reynolds number within the chamber is less than the Reynolds number in the inlet and exit tubes by a factor of about $1 / 2.8$ Based on the rule of thumb that thrombi develop in "low-flow" regions, the chamber constitutes a preferential site for thrombus development relative to the connecting inlet and outlet tubes.

The principal fully developed flow regimes associated with this device are:

A. laminar-helical

B. laminar-cellular or Taylor-vortex

C. turbulent

At low axial flow rates and at low shaft rotation speeds of the shaft, the flow through the chamber is helical in pattern. The idealized fully developed helical flow pattern for constant flow in this device is shown in Figure 6(A). Under these circumstances, the flow in the axial direction and the tangential

$\S \frac{\operatorname{Re}(\text { chamber })}{\operatorname{Re} \text { (entry tube) }}=\frac{\mathbf{R}_{\mathbf{T}}}{\mathbf{R}_{\mathbf{1}}+\mathbf{R}_{2}}$

$\mathbf{R}_{\mathrm{T}}=$ radius of tube, $\mathbf{R}_{1}=$ radius of shaft, $\mathbf{R}_{2}=$ radius of cylinder. 


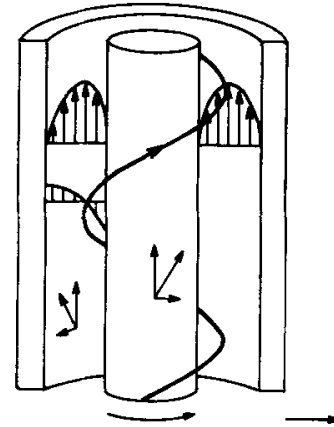

(A)

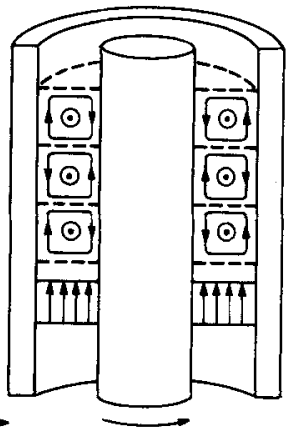

(B)
Figure 6. Flow regimes in couette biomaterial test chamber.

ABOVE CRITICAL rpm

(or angular) flow in the circumferential direction are independent of each other (for Newtonian fluids), and the net flow is the vector sum of these two independent flow patterns. Shown in the figure is the axial parabolic flow pattern that exists between the central shaft and the coaxial cylinder. Above a critical shaft rotational speed the flow pattern changes to that shown in FIGURE 6 (B). But all biomaterial evaluations were made below this critical speed, i.e., in the laminar-helical regime.

The flow in the chamber is actually pulsatile in nature (see FIGURE 17 and below), but this pertubation does not drastically alter the transport behavior in the test chamber.

\section{METHODS}

\section{Labeled Blood Elements}

Measurements of the rate of thrombus development involved the use of radioisotope-labeled fibrinogen and platelets. Previous works by Olson et al. ${ }^{13},{ }^{\text {14 }}$ demonstrated the use of labeled blood elements for the determination of the amount and composition of a thrombus. It was shown that by labeling platelets with chromium-51, and fibrinogen with iodine-125, and by monitoring these simultaneously, the relative amounts of these blood elements in a thrombus is obtained.

Autologous platelets were labeled as follows. ${ }^{15}$ One day prior to an experiment, blood $(500 \mathrm{ml})$ was withdrawn from the animal; the platelets were separated, washed, labeled with ${ }^{11} \mathrm{Cr}$ and, along with the erythrocytes, were reinfused. The peak platelet radioactivity after infusion ranged from 100 to $1000 \mathrm{cpm} / \mathrm{ml}$ of whole blood.

Also, on the day prior to an experiment ${ }^{125}$ I-labeled human fibrinogen was injected. The peak level of radioactivity in whole blood after infusion was about $10 \times 10^{3} \mathrm{cpm} / \mathrm{ml}$.

A dual channel counter was placed over the test chambers to monitor the

If Amersham-Searle. 
total amount of radioactivity (FIgURE 7). It can be seen in Figure 8 that ${ }^{51} \mathrm{Cr}$ gives some low-energy emission which interferes with the iodine counts; however, an energy window can be selected that minimizes interference in the ${ }^{51} \mathrm{Cr}$ channel from ${ }^{125} \mathrm{I}$. There is a simple formula for the correction of spillover of ${ }^{51} \mathrm{Cr}$ into the ${ }^{125}$ I channel.

The field of view detected by the sodium iodide crystal is shown in FigurE 9. The crystal diameter is approximately $33 \mathrm{~mm}$. A $1-\mathrm{mm}$ "point" source of ${ }^{51} \mathrm{Cr}$ was placed at different lateral distances from the center of the crystal and

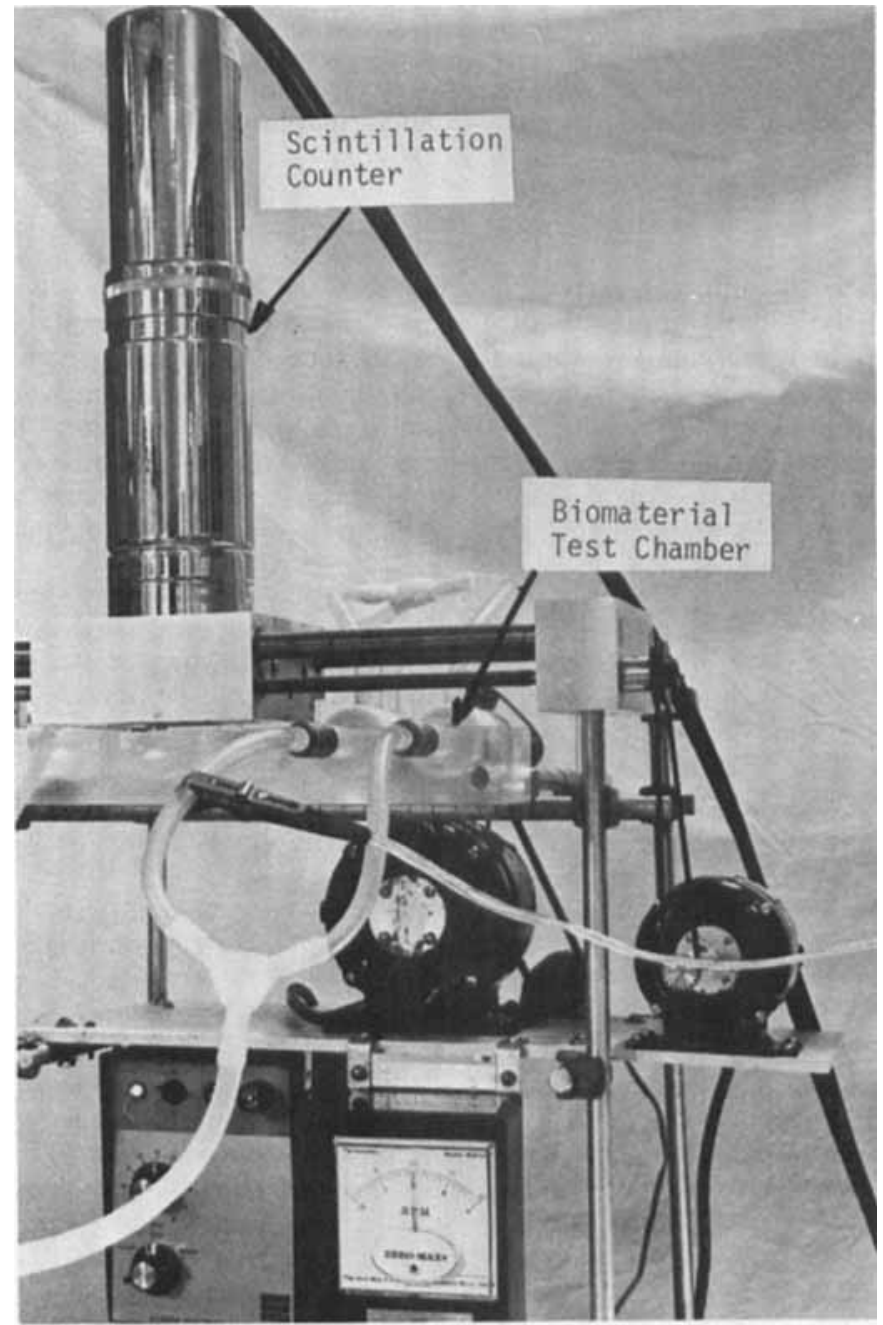

FIGURE 7. Photograph of test chambers in position for monitoring of accumulated radioactive blood elements. Sodium iodide crystal detector (vertical component) is translated over each chamber in turn at five-minute intervals. 


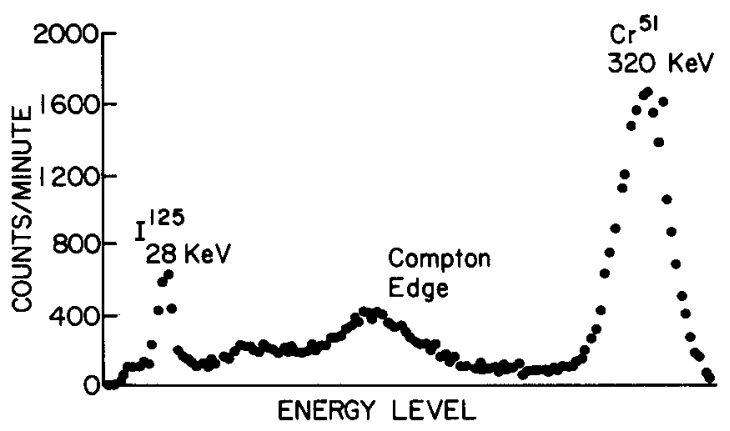

FIGURE 8. Energy spectrum of gamma-emitting isotopes used for labeling blood elements. Platelets were labeled with ${ }^{51} \mathrm{Cr}$ and fibrinogen was labeled with ${ }^{125} \mathrm{I}$.

on two planes at different vertical heights from the crystal. The 4-mm height represents the closest approach of the test chamber to the crystal, and the $10-\mathrm{mm}$ height represents the approximate distance of the shaft to the crystal. At the distance of the shaft from the crystal, $10 \mathrm{~mm}$, the apparent field of view of the counter is approximately $25-30 \mathrm{~mm}$ to each side of center. This means that an approximate length of $60 \mathrm{~mm}$ of the shaft in the test chamber is counted at any time. Also, since the center to center distance of the adjacent chambers in our multiple chamber apparatus is $40 \mathrm{~mm}$, there is very little interference from adjacent chambers.

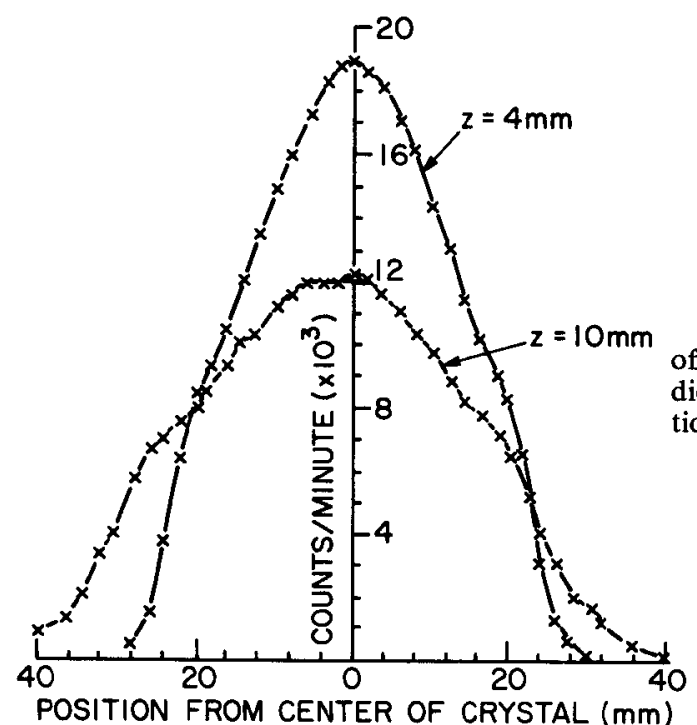

FIGURE 9. Calibration of sensitivity of $\mathrm{NaI}$ crystal to point sources of radioactivity placed in different positions. 
Test Procedure

Chambers were assembled with new shafts and cylinders for each biomaterial test and connected into the A-V neck shunt by means of $1 / 4$ in I.D. Silastic tubing. The tubing and the chamber assembly were filled with saline and then attached to the clamped shunt; after making sure that there were no trapped air bubbles, the clamps were released to allow the blood to flow. Anticoagulants were not used except as noted below. The deposition of platelets and fibrinogen within the chamber was monitored at five-minute intervals with a dual-channel scintillation counter.

Blood flow rate through the chamber was controlled at $200 \mathrm{ml} / \mathrm{min}$, and the shaft rotation speed was maintained at $200 \mathrm{rpm}$. Under these conditions the flow in the chamber is within a laminar flow regime.

Experiments were carried out for periods of one hour. After completion of each experiment, the chamber was flushed with saline; from the total monitored radioactivity, the individual contributions of shaft and wall deposits were determined. The thrombi were then removed from the shaft, blotted, and weighed. In many instances the thrombi were removed in four equal sections to determine the distribution of the deposit along the length of the shaft. Then the individual pieces were placed in counting vials and the total ${ }^{51} \mathrm{Cr}$ and ${ }^{125} \mathrm{I}$ isotope content determined with a well counter.

The fact that the shaft in this test-chamber configuration seems to be more thrombogenic than the shell is fortunate but cannot be explained by conventional notions as to the effect of flow and velocity profiles on rates of thrombus formation. Whatever the cause, the fact that the shaft represents a more thrombogenic environment than the cylinder wall ensures that the results will not be complicated by large amounts of thrombus formation on the shell. Therefore, it is expected that thrombogenicity comparisons of materials can be made by using shafts coated with different materials, whereas a single type of surface coating is used on the inner wall of the cylinder.

\section{RESULTS}

\section{Rate of Thrombus Formation}

Typical accumulation patterns of platelets and fibrinogen within the test chamber are shown in FiguRE 10. Generally, the increase in either isotope was linear with time over the standard one-hour test period. The initial radioactivity values were related to the "background" volume of blood within the chamber. The radioactivity monitored over a control section of the return tubing remained at the same level during the course of an experiment, suggesting no major consumption of platelets or fibrinogen. However, samples taken for hematology showed about a $25 \%$ loss in platelets and fibrinogen. The appearance of a typical thrombus formed on the shaft is shown in FIGURE 11.

To evaluate the systemic effects of labeling platelets and of subsequent material tests, blood samples were taken before labeling, one hour after reinfusing platelets, before a material test (usually the next morning), and after each test period of about 90 minutes duration. A follow-up sample was taken on the next day to determine the extent of recovery.

The results of ten experiments are shown in Figure 12. The largest effect 


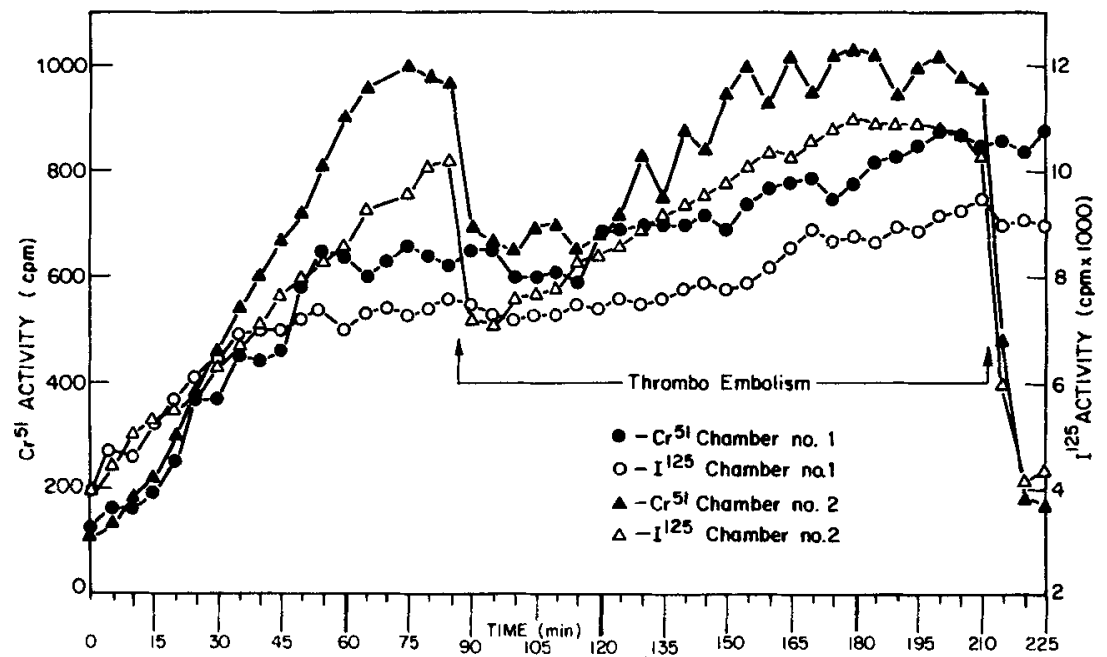

FIGURE 10. Accumulation patterns of radioactivity-labeled platelets $\left({ }^{51} \mathrm{Cr}\right)$ and fibrinogen $\left({ }^{205} \mathrm{I}\right)$ in biomaterial test chambers. Simultaneous reductions in platelet and fibrinogen radioactivity in chamber 2 are indications of thromoembolism.

of the test procedure was on platelet count, which dropped about $40 \%$ during three hours of testing. There was some indication that the platelet count is stabilized after this period and that it shows substantial recovery by the next day. On the other hand, fibrinogen levels were only mildly affected by the test apparatus, and the recovery was somewhat slower. An almost parallel pattern was found by counting the ${ }^{51} \mathrm{Cr}$ and ${ }^{125} \mathrm{I}$ content of whole-blood samples during the same periods, as shown in TABLE 1. This correlation provides further evidence that the labeled platelets and fibrinogen are reflecting the behavior of the total population.

PTT values showed some increase, indicating some depletion of clotting factors during the test period, but a full recovery of PTT by the next day was observed. These changes in the coagulation system may explain, to some extent, the observation that the amount of thrombus formed decreased with sequential tests. It should be recalled, however, that for the different animals used in these

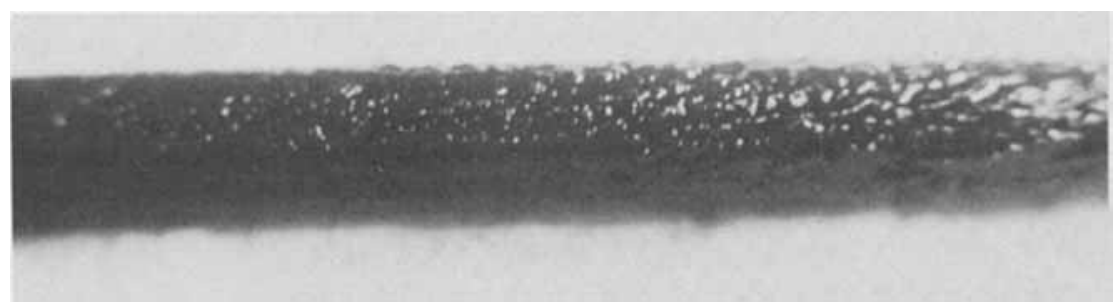

FIGURE 11. Close-up photograph of a typical thrombus formed on a stainless-steel rod. 


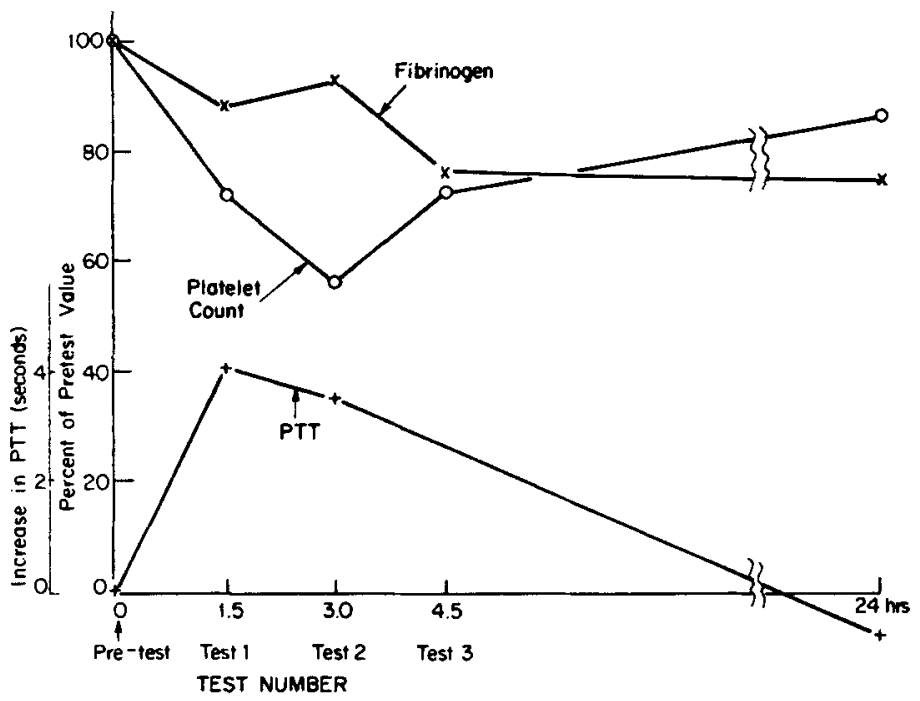

FIGURE 12. Systemic hemotology patterns in the dog during and after several sequential biomaterial testing procedures on the same day.

studies, the platelet count and fibrinogen levels varied by as much as $50 \%$ from animal to animal. And, although these variations influenced thrombus formation, the magnitude of the effect was less than that of sequential tests on the same animal.

\section{Thrombus Composition}

The average platelet and fibrinogen content of the thrombi formed on stainless steel shafts in the ex vivo test chamber are given in TABLE 2 . These results, which are averages of 20 runs, are compared with some other published

\section{TABLE 1}

Comparison of Clinical and Radioisotope Methods for Platelet and Fibrinogen Content of Blood During Biomaterials Test Procedure

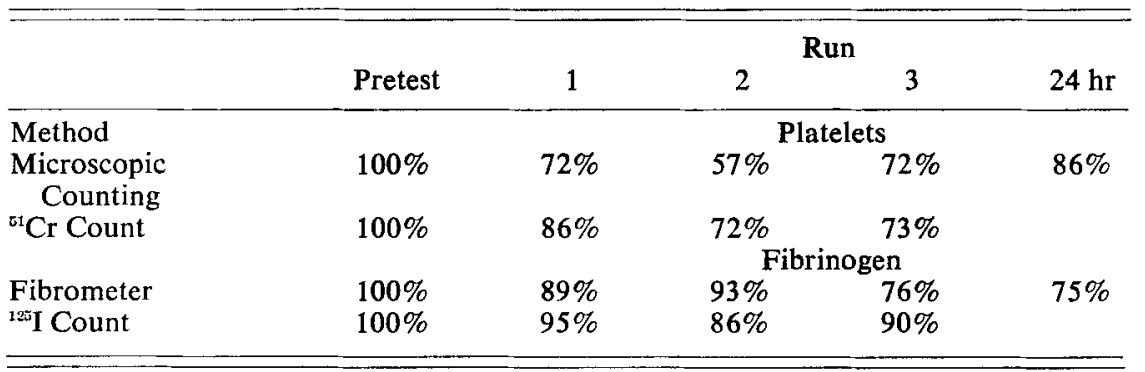




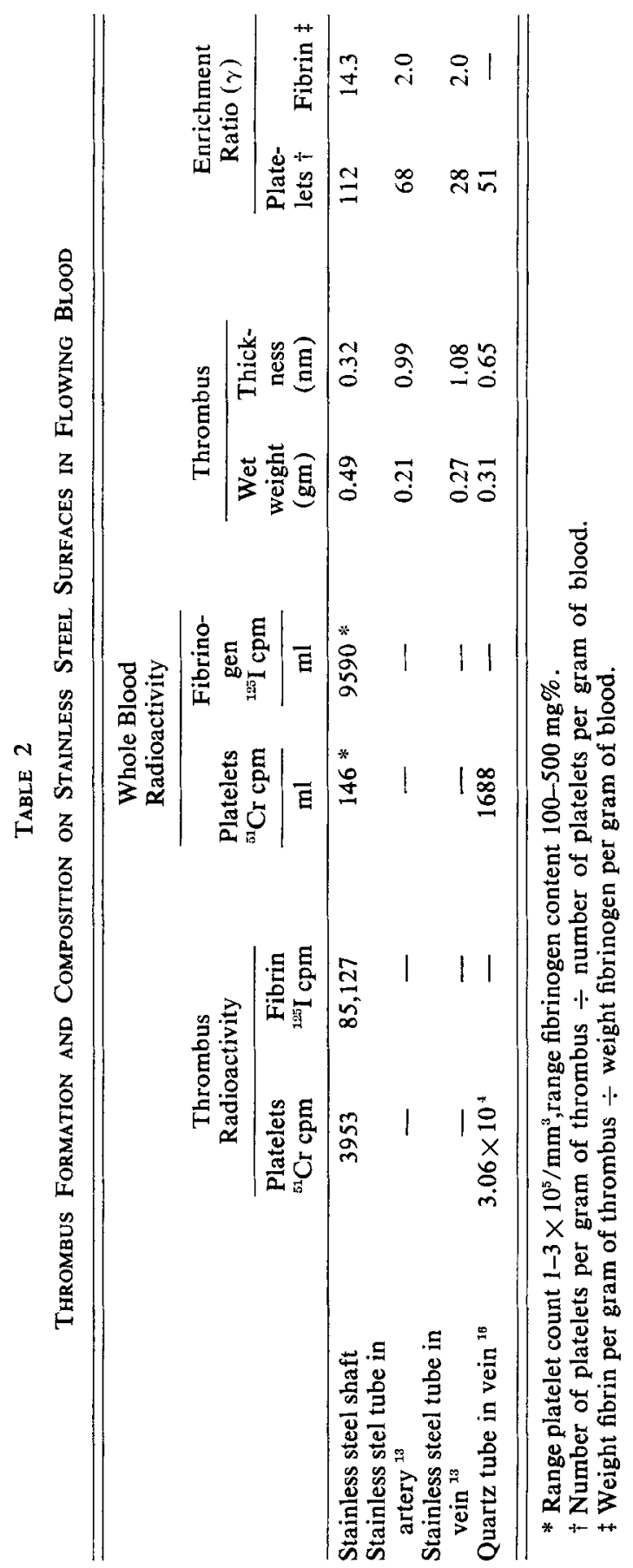


experiments on thrombus formation in the absence of anticoagulants. The first two columns give the radioactivity values for the entire thrombus as determined by the well counter. The next two columns give the ${ }^{51} \mathrm{Cr}$ and ${ }^{125} \mathrm{I}$ counts per $\mathrm{ml}$ of whole blood taken from the animals before the test period. The fifth column gives the wet weight of thrombus accumulated on the shaft. By assuming a specific gravity of 1.0 , an estimate of the mean thickness was obtained.

In order to compare results from different animals and different tests, it is useful to calculate the ratio of the specific activity of the thrombi divided by the specific activity of blood for the same experiment. These results, given in columns 7 and 8 , show the relative concentration of platelets and fibrin in thrombi as compared to whole blood.

The platelet content of thrombi (platelets per unit volume) was up to $112 \pm 105$ times that of whole blood. This enrichment ratio compares with a value of 68 obtained by Olson et al. ${ }^{13}$ for stainless steel tubes placed in the carotid artery, and with a value of 28 for tubes placed in the jugular vein after one hour of exposure time. Foster and Dobell ${ }^{16}$ also determined the platelet content of thrombi formed on quartz tubes placed in the thoracic vena cava for two hours and found an average thrombus/blood ratio of 51. Considering the differences in these experiments, the values are remarkably similar.

The fibrin content of thrombi formed in our system averaged about $14.3 \pm 7.3$ times that of whole blood. Olson et al.13 found a lower fibrin content in his implanted tubes, reporting an enrichment ratio of approximately two for both arterial and venous locations.

Some trends were observed with respect to the composition of thrombi as related to size. A regression analysis showed that the inverse relationship platelet content of thrombus $=\alpha\left(\frac{1}{\text { thrombus weight }}\right)$ is significant at the 0.002 level. This indicates that the larger thrombi have a proportionately larger amount of red blood cells and that the size of the thrombus may be the distinguishing feature between the so-called venous "red clots" and the arterial "white thrombi."

Based on enrichment ratios, an estimate of the ultimate sensitivity of the current monitoring system can be made. One can have reasonable confidence in a change detected by the scintillation counter if the radioactivity, due to the accumulated thrombus, increases more than twice the baseline level due to blood in the chamber initially. The approximate thrombus thickness, $\Delta$, that can be detected for different values of the enrichment ratio $\gamma$ is given by

$$
\Delta=\left(\frac{\mathbf{R}_{2}^{2}+(\gamma-2) \mathbf{R}_{1}^{2}}{\gamma-1}\right)^{1 / 2}-\mathbf{R}_{1}
$$

where $R_{2}$ and $R_{1}$ are the radii of outer cylinder and shaft, respectively. For our apparatus the relationship between the minimum detectable thrombus thickness, $\Delta$, and thrombus radioactivity enrichment ratio, $\gamma$, is given in TABLE 3 .

Based on our values of $\gamma$ of about 110 for platelets and 15 for fibrinogen, an approximate minimum thrombus thickness of $0.05 \mathrm{~mm}$ by ${ }^{51} \mathrm{Cr}$-labeled platelets and $0.3 \mathrm{~mm}$ by ${ }^{125} \mathrm{I}$-labeled fibrinogen can be detected.

\section{Discussion}

The primary purpose of this study was to evaluate the thrombogenicity of different biomaterials in contact with blood. A number of other factors, how- 
ever, were found to influence the rate and amount of thrombus accumulation in the test chamber, and these led to the concept of running parallel tests to obtain the best comparative information.

\section{Effect of Biomaterial}

In order to evaluate the response of the test procedure to different materials, a large number of runs were made with etched 303 stainless steel and Silastic**-coated shafts. Photomicrographs of these two surfaces, along with a comparative picture of a thrombus, are shown in FIGURE 13. Greater amounts of thrombus appear to form on the stainless steel surface. As shown in TABLE 4, data pooled from all runs at different flow rates, different shaft rotation speeds, and in different animals gave an average wet weight of 0.74 grams for thrombus formed on the stainless steel surface, in contrast to 0.48 grams formed

TABle 3

Sensitivity of Radioisotope Technique for Measuring Thrombus Thickness

\begin{tabular}{cc}
\hline $\begin{array}{c}\text { Thrombus Enrichment } \\
\text { Ratio }(\gamma)\end{array}$ & $\begin{array}{c}\text { Minimum Detectable } \\
\text { Thrombus Thickness } \\
\text { (microns)* }\end{array}$ \\
\hline 5 & 920 \\
10 & 447 \\
25 & 176 \\
50 & 88 \\
100 & 44 \\
150 & 29 \\
\hline
\end{tabular}

* For $\mathrm{R}_{1}=0.238 \mathrm{~cm} . \mathrm{R}_{2}=0.515 \mathrm{~cm}$.

on the silicone rubber surface. The significance of this difference is at the $95 \%$ level. If only those data for "standard" runs with a flow of $200 \mathrm{ml} / \mathrm{min}$ and a shaft speed of $200 \mathrm{rpm}$ are considered, there still is greater amount of clot formed on the stainless surface, 0.49 grams vs. 0.39 grams. But the variability of the data does not permit assignment of statistical significance to this difference.

However, a comparison of parallel experiments in an animal at a given flow condition offers the most reliable evaluation. Values on the last line in TABLE 4 indicate that the size of thrombus formed on 303 stainless steel was about $70 \%$ greater than on Silastic when both materials are tested simultaneously. Also, the variance of the data obtained in this fashion, i.e. paired comparisons, is the lowest found in this study.

** Dow Corning Medical Grade Adhesive 819 was dispersed in toluene and the shafts were dip-coated in this preparation. 
TABLE 4

Comparison of Thrombus Formation on Stainless Steel and Silastic Rubber Surfaces

\begin{tabular}{lccccccc}
\hline \hline & \multicolumn{2}{c}{ Thrombus Weight (grams) } & & & Number \\
$\begin{array}{c}\text { Test } \\
\text { Conditions }\end{array}$ & $\begin{array}{c}\text { Stainless } \\
\text { Steel }\end{array}$ & $\begin{array}{c}\text { Silastic } \\
\text { Rubber }\end{array}$ & $\begin{array}{c}\text { Differ- } \\
\text { ence }\end{array}$ & $\begin{array}{c}\text { Ratio } \\
\text { Weights } \\
\text { Obser- } \\
\text { vations }\end{array}$ & $\begin{array}{c}\text { Lance } \\
\text { Level }\end{array}$ \\
\hline $\begin{array}{l}\text { All runs } \\
200 \mathrm{rpm}, 200 \\
\text { ml/min runs }\end{array}$ & $0.74 \pm 0.65$ & $0.48 \pm 0.59$ & 0.26 & 1.54 & 87 & $0.06^{*}$ \\
$\begin{array}{c}\text { All paired runs } \\
200 \mathrm{rpm}, 200 \mathrm{ml} / \\
\text { min paired runs }\end{array}$ & $0.49 \pm 0.33$ & $0.39 \pm 0.37$ & 0.10 & 1.25 & 60 & 0.32 \\
\hline
\end{tabular}

* Highly significant.

** Moderately significant.

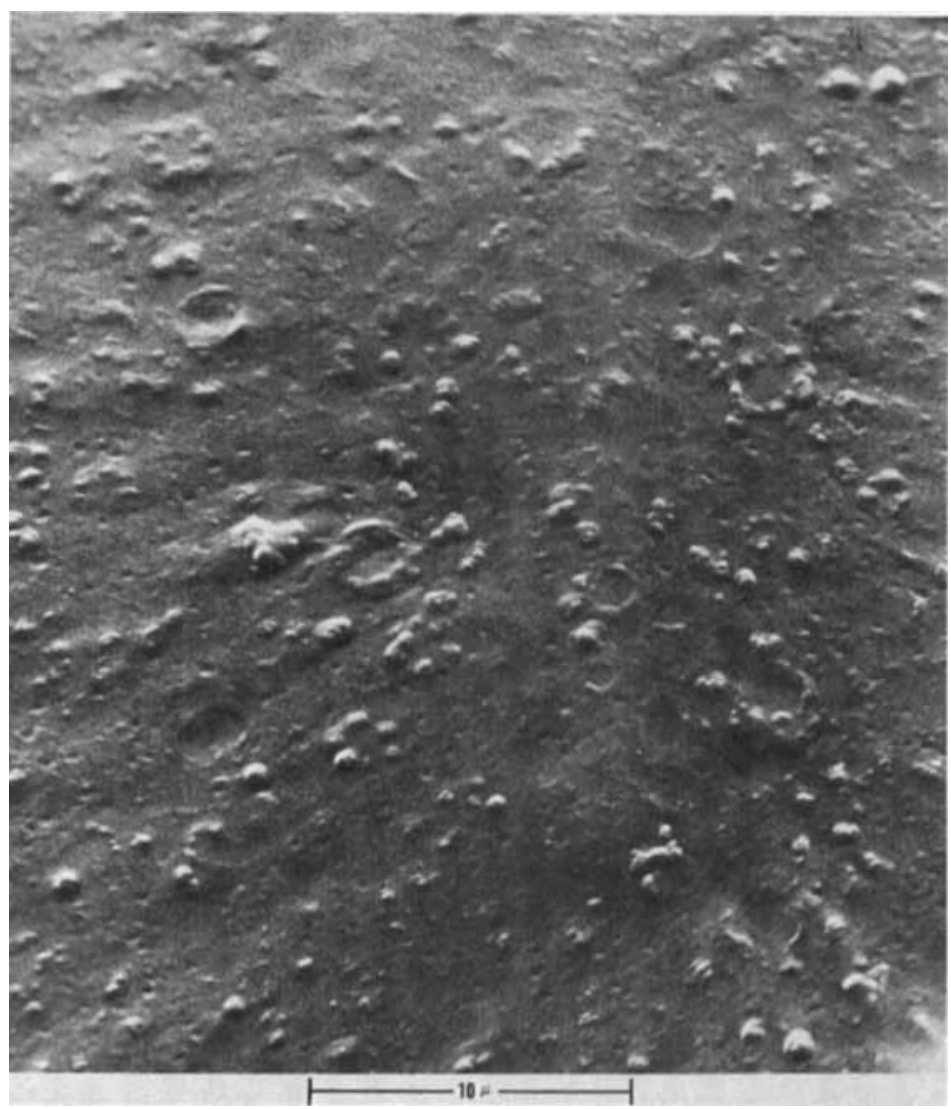

FIGURE 13a. Scanning electron micrographs of surfaces used in the evaluation of the ex vivo biomaterial testing procedure. Silastic rubber (coating made by dipping stainless-steel rod in a dispersion of Dow-Corning Silastic Medical Adhesive). 


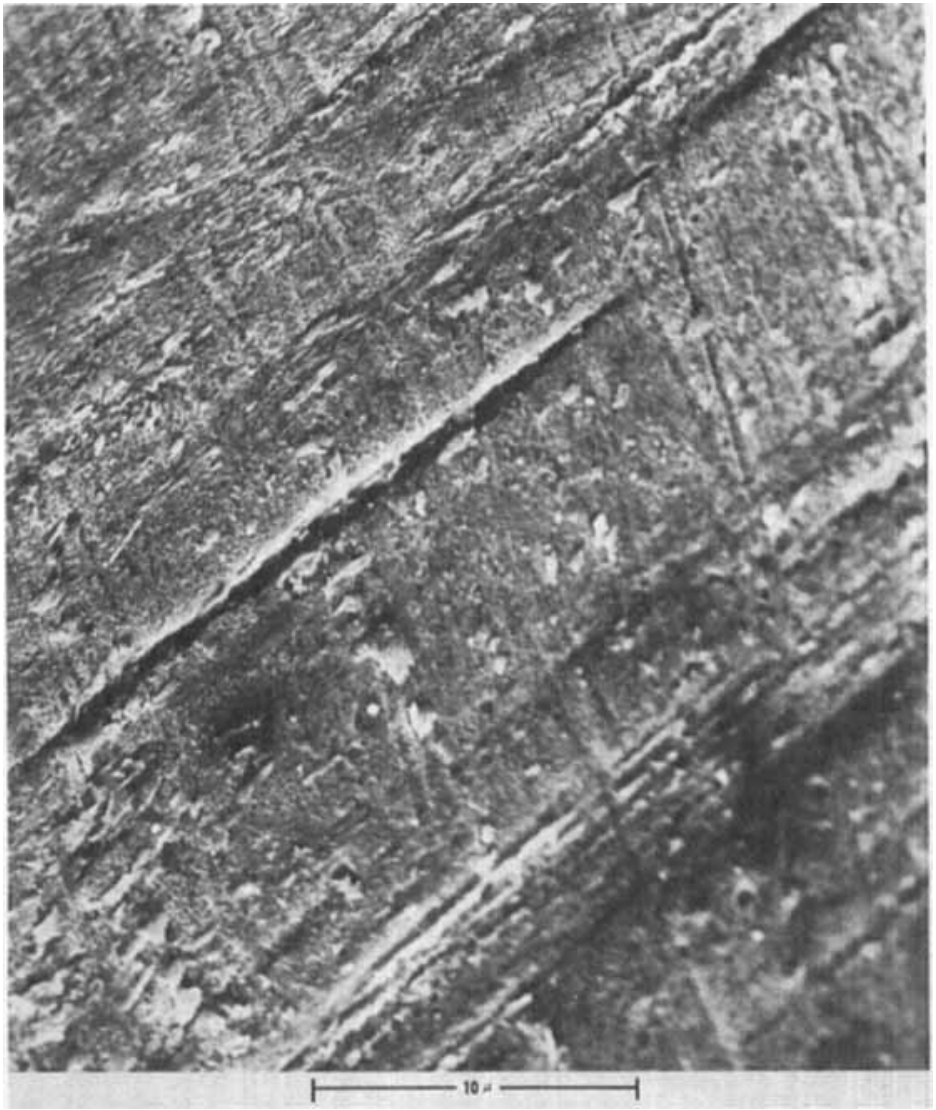

FIGURE 13b. Etched 303 stainless steel. (See Figure 13a legend.)

\section{Effect of Anticoagulants}

In a number of experiments, heparin at a level of $60 \mu / \mathrm{kg}$ was administered to the animal one half hour before initiating the biomaterial test procedure. Assays of systemic blood samples during the procedure showed that heparin disappeared from the circulation in about 45 minutes. Coincident with heparin disappearance, thrombus accumulation, as measured by the scintillation counter, began. The amount of thrombus adhering to the shaft surface was less after a dose of heparin, and the distribution was different, with some thrombus formed both on the inner surface of the cylinder and on the shaft surface.

Although the amount of thrombus formed on the shaft was slightly lower than for the tests conducted in the absence of heparin, the results were much more consistent from test to test. In addition, the difference in thrombus weight between Silastic and stainless was greater. 


\section{Embolization}

One factor often considered important in evaluating biomaterials is the amount of embolization due to the presence of biomaterials in the bloodstream. These test procedures do not measure embolization except as indirectly reflected in an abrupt decrease in the amount of radioactivity in the chamber during the test. This type of decrease was not observed during our normal one-hour test period. In some cases where tests extended up to four hours, however, abrupt drops in radioactivity in the chamber were observed. An example is shown in FIGURE 10. The simultaneous abrupt changes in amounts of platelets and fibrin in the chamber indicate that some embolization took place with subsequent thrombus reformation, the amount of embolization being reflected by the differ-

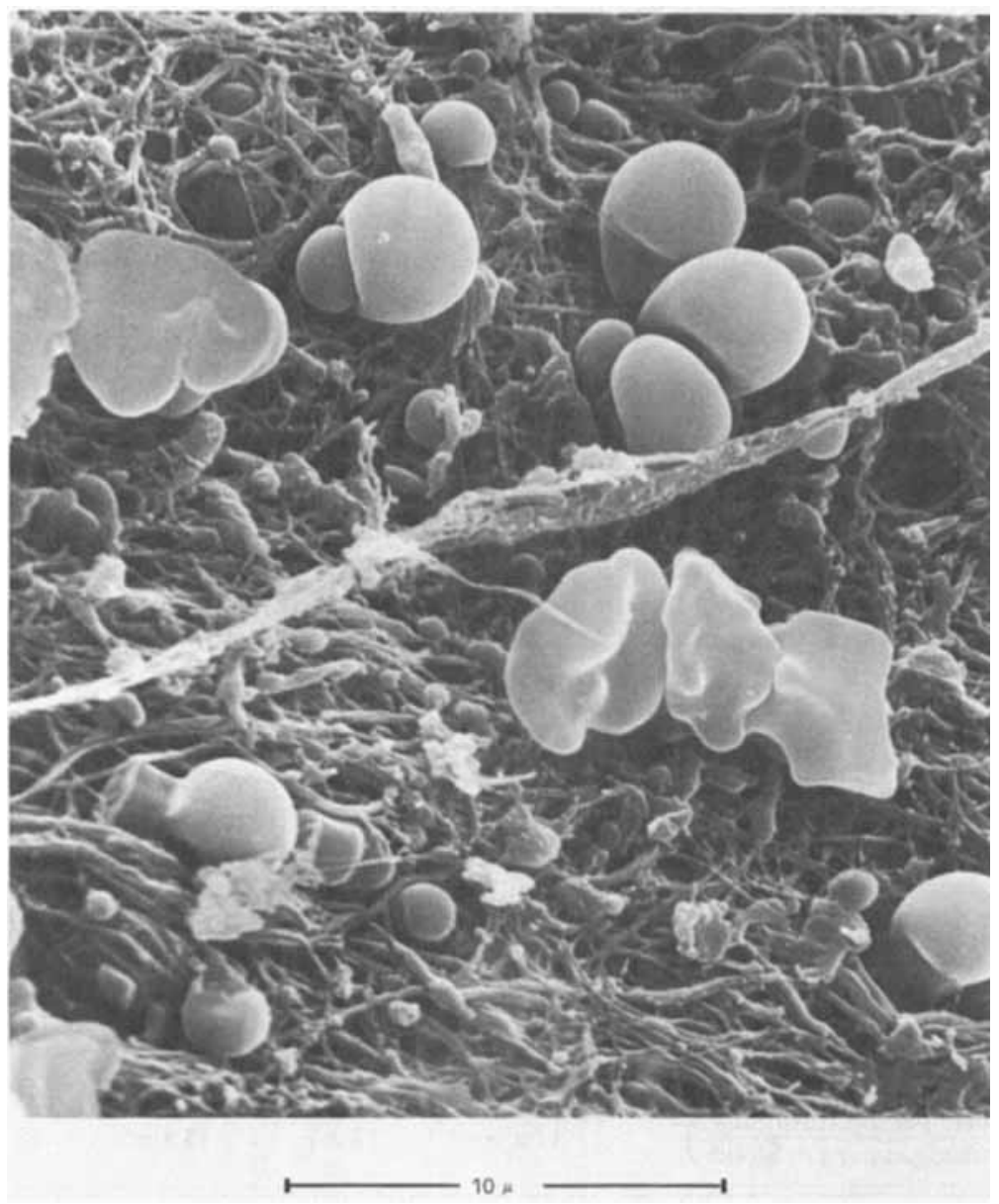

FIGURE 13c. Scanning electron micrograph of a thromus formed in the test apparatus. 
ence in radioactivity after the abrupt change. The embolization in this particular animal did not cause any visible untoward effects after the test.

\section{Effect of Sequential Tests}

A most consistent observation was that the weight of thrombus varies with the order of testing in a sequential series of tests on the same day. Generally, the weight of the thrombus decreases from the first to last test. For example, in TABLE 5 the average weight of clots at a specific flow condition, $200 \mathrm{ml} / \mathrm{min}$ and $200 \mathrm{rpm}$, decreases from approximately 0.55 grams on the shaft for the first test to 0.21 grams of clot for the fourth test. An analysis of variance showed that this effect was significant at the 0.003 level.

The decreases in platelet and fibrinogen levels during the test period shown in FIGURE 12 appear to correlate with diminished thrombus formation. The variance of the observation for each test period decreases with time, an indication that the system becomes more stable or reproducible for tests carried out after one to two hours of testing and that the most variable observations are in the first hour of testing. In the last line of TABLE 5 there is a trend that suggests that the composition of the clot may be changing during sequential periods of testing. The relative fibrin content of the clot was lowest during the first period and increased for the last period of testing. This observation may reflect an increase in circulating coagulants that promote a more rapid rate of fibrin formation.

\section{Flow and Transport Characteristics of the Test Chamber}

In the laminar regime, the flow pattern of a Newtonian fluid in the annular space between a stationary cylinder and a rotating shaft is well known. The pertinent equations for velocities and shear rates are given in the appendix. The resulting flow pattern and direction of shear forces are given by the vector resultant of axial and angular components, as illustrated in FIGURE 6(A). Some typical values of shear rates based on fully developed flow and calculated for

TABLE 5

Results from Sequential Biomaterial Tests on Same Day

\begin{tabular}{|c|c|c|c|c|}
\hline & \multicolumn{4}{|c|}{ Run } \\
\hline & $A$ (First) & $\mathrm{B}$ & $\mathrm{C}$ & $\mathrm{D}$ (Last) \\
\hline Thrombus weight (grams) & $0.5 \pm 0.4$ & $0.5 \pm 0.4$ & $0.4 \pm 0.2$ & $0.2 \pm 0.1$ \\
\hline $\begin{array}{l}\text { Platelet enrichment ratio } \\
\left(\frac{\text { no. per gm thrombus }}{\text { no. per gm blood }}\right)\end{array}$ & $120 \pm 100$ & $100 \pm 70$ & $100 \pm 50$ & $140 \pm 30$ \\
\hline $\begin{array}{l}\text { Fibrinogen enrichment ratio } \\
\left(\begin{array}{c}\text { Fibrin per gm thrombus } \\
\text { Fibrinogen per gm blood }\end{array}\right)\end{array}$ & $11 \pm 6$ & $12 \pm 7$ & $13 \pm 6$ & $18 \pm 3$ \\
\hline
\end{tabular}

Blood flow $(\mathrm{ml} / \mathrm{min})$ through test chamber $200 \mathrm{ml} / \mathrm{min}$, shaft rotation speed 200 (rpm). 


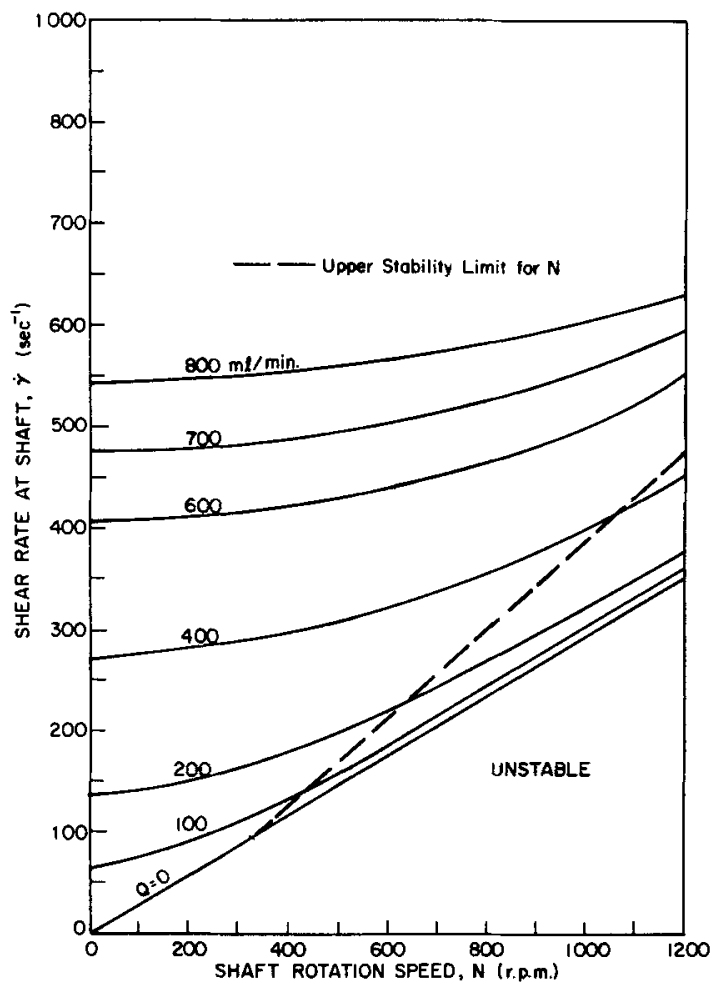

FIGURE 14. Effect of flow rate and shaft rotation speed on shear rate at the surface of the surface of the shaft. Dashed line indicates the boundary between the laminar helical-flow pattern regime and the unstable Taylor-vortex regime.

the chamber used in these experiments are given in Figure 14. As can be seen, the net shear on the central shaft is almost a direct function of the rotational speed. However, the shear on the shaft surface is also affected by axial flow rates through the chamber, so that at high axial flow rates the relative effects of rotational speed are, to some extent, diminished. The effect of rotational speed on shear stress at the shaft is more pronounced at either low axial flow rates or larger gap widths. There is very little effect of shaft rotation speed upon the shear stress on the outer cylindrical wall.

In the absence of density variations and before the onset of Taylor vortices, the mass transfer coefficients on the shaft and on the wall are independent of rotation. It is in this range, therefore, that it is possible to distinguish between the mechanical effects of shear and its effect on transport phenomena. Comparing Figure 14 with Figures $15 \mathrm{~A} \& 15 \mathrm{~B}$, for example, at an axial flow rate of $140 \mathrm{cc} / \mathrm{min}$ the mass transfer coefficient, as reflected in the Sherwood number (Sh), remains constant up to a shaft speed of $300 \mathrm{rpm}$, whereas the shear stress is increasing on the shaft.

Another factor to be considered is the axial dependence of mass transfer coefficients on the shaft and cylindrical surfaces. In the laminar flow regime 


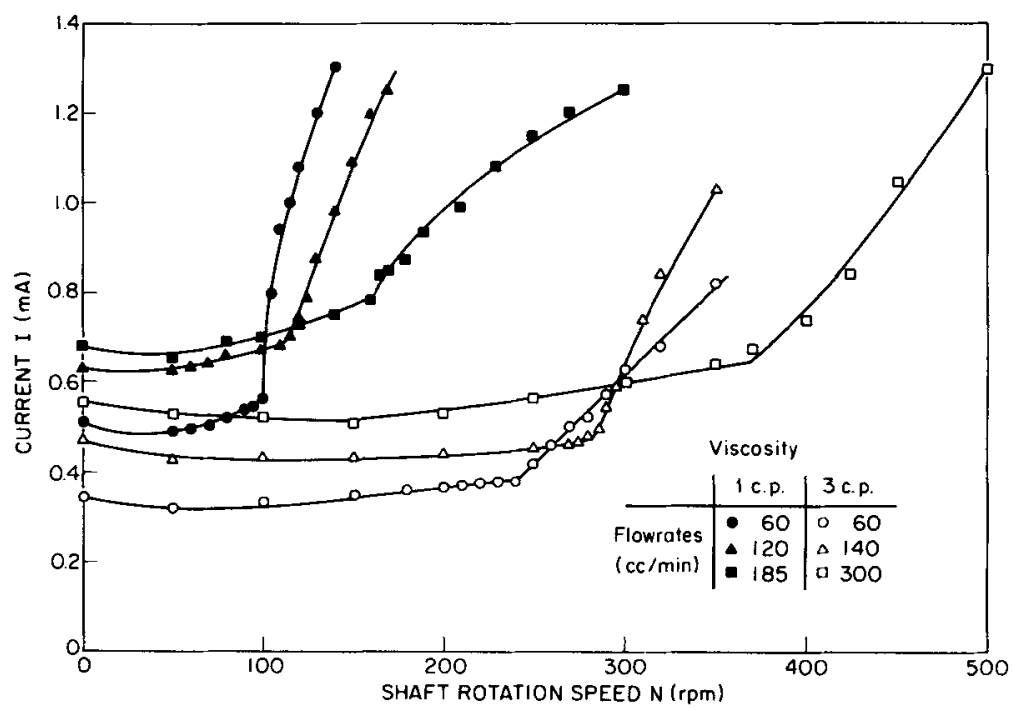

Figure 15a. Polarographic measurement of mass-transfer coefficients at the surface of the shaft as a function of rotation speed, flow rate, and viscosity. Measured current is directly related to mass transfer coefficients. Breaks in curves are a result of the onset of unstable Taylor-vortices.

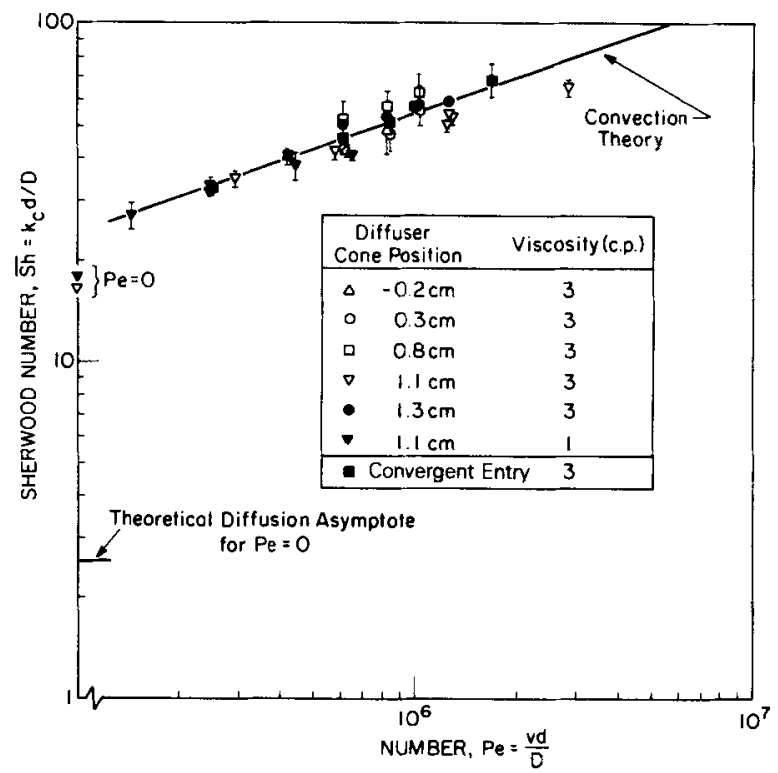

FIGURE 15b. Mass-transfer data from the laminar helical-flow regime correlated with dimensionless Pe number. (See Figure 15a.) 
there is a developing concentration boundary layer from the tip of the shaft to the exit portion. If the flow field of Figure 6(A) is assumed, then a theoretical calculation of steady-state mass transfer coefficients can be made by a modification of the classical asymptotic Leveque formula ${ }^{17}$ (see APPENDIX).

As the rotation rate is increased in the helical flow regime, a critical speed is finally attained where the flow becomes unstable. A new flow regime with radial motion ensues, and Equation 5 is no longer valid. In this regime, depicted on the right-hand side of the FIGURE 6, a cellular flow pattern with "Taylor vortices" emerges. These vortices have the appearance of smoke rings stacked one upon another, with the circulation in alternate rings opposing. This vortex regime persists to much higher rotational speeds, whereupon "wavy" vortices are formed, and finally turbulence is achieved. The flow pattern of the Taylor vortices is similar to that used by other workers to study thrombus formation such as the captured-vortex device of Leonard and Litwak ${ }^{3}$ and the standing vortex in an expansion section, studied by Goldsmith. ${ }^{18}$

During blood flow through the chamber, thrombi may form on the internal wall of the cylinder as well as on the rotating shaft, and a significant gap width was considered necessary to avoid occlusion of the annular space during extended experimental periods. Therefore, our device falls into the "wide-gap" couette-flow category, where theoretical stability analysis has not been as extensive. Some mass transfer studies were done in order to characterize the transport rates or fluxes to the shaft surface as a function of rotational speed and axial flow rate and the critical speeds for the transition to Taylor vortices. These are described more extensively below.

\section{Theoretical Prediction of Hydrodynamic Stability}

The helical (Poiseuille-Couette) flow in the annulus between coaxial circular cylinders of a Newtonian fluid is characterized by two dimensionless parameters, an axial flow Reynolds number

$$
\operatorname{Re}=\frac{\mathrm{Ud}}{\nu}=\frac{\mathrm{Q}}{\pi\left(\mathrm{R}_{1}+\mathrm{R}_{2}\right) \nu}
$$

and a rotational Taylor number

$$
\mathrm{Ta}=\frac{\Omega^{2} \mathbf{R}_{1} \mathrm{~d}^{3}}{\nu^{2}}
$$

where

$\mathrm{U}=$ mean axial flow velocity in the annulus $=\mathrm{Q} / \pi\left(\mathbf{R}_{2}{ }^{2}-\mathbf{R}_{1}{ }^{2}\right)$

$\mathrm{Q}=$ axial volumetric flow rate $\left(\mathrm{cm}^{3} / \mathrm{sec}\right)$

$\mathbf{R}_{2}=$ outer cylinder (chamber) radius $(\mathrm{cm})$

$\mathbf{R}_{1}=$ inner cylinder (shaft) radius $(\mathrm{cm})$

$\mathbf{d}=\mathbf{R}_{2}-\mathbf{R}_{1}=$ annular gap width, $(\mathrm{cm})$

$\nu=\mu / \rho=$ kinematic viscosity of fluid $\left(\frac{\mathrm{cm}^{2}}{\mathrm{sec}}\right)$

$\Omega=$ angular velocity of outer cylinder $(\mathrm{rad} / \mathrm{sec})=2 \pi \mathrm{N}$

$\mathrm{N}=$ rotational speed $(\mathrm{rev} / \mathrm{sec})$

As mentioned above, the laminar helical flow becomes unstable at a critical 
shaft rotational speed $\mathrm{N}_{c}$. This is properly characterized by a critical rotational Taylor number $\mathrm{Ta}_{\mathfrak{c}}$, which depends on the axial flow Reynolds number Re.

To date, no complete stability theory exists for arbitrary radius ratios $\eta=\mathbf{R}_{1} / \mathbf{R}_{2}$ and flow Reynolds numbers. Theoretical results are, however, available for zero axial flow, $\operatorname{Re}=0$, at over an extended range of $\eta$, as well as for the thin gap limit, $\eta \rightarrow 1$, at moderate Reynolds numbers. TABLE 6 summarizes results given by Sparrow et al. ${ }^{10}$ for the first case.

For the second case, the thin gap, several investigators (Chandrasekhar, ${ }^{20}$ Datta, ${ }^{21}$ Krueger and Di Prima, ${ }^{22}$ and Hughes and Reid ${ }^{23}$ ) have made theoretical studies on the influence of Re. According to Hughes and Reid the theoretical results for $\operatorname{Re}<500$ appear to be reasonably well represented by a formula proposed by Datta ${ }^{21}$ :

$$
\mathrm{Ta}_{\mathrm{c}}=1708+2.35 \mathrm{Re}^{2}
$$

which actually should be accurate only for very low Reynolds numbers. This relation can be empirically extended in the form

$$
\frac{\mathrm{Ta}_{\mathrm{c}}}{(\mathrm{Ta})_{0}}=1+1.38 \times 10^{-3} \mathrm{Re}^{2}
$$

where $\left(\mathrm{Ta}_{\mathrm{c}}\right)_{0}$ denotes the critical Taylor number for zero axial flow, $\mathrm{Re}=0$, as given in TABLE 6.

TABLE 6

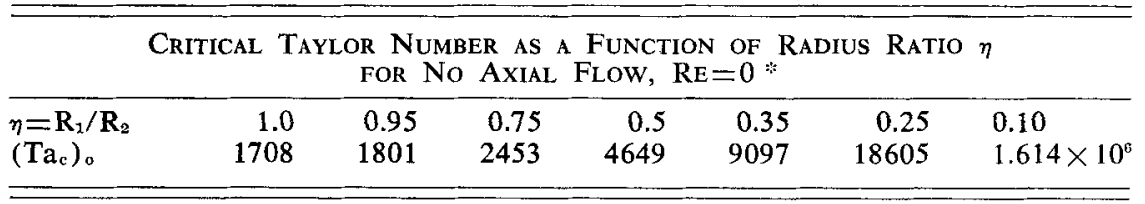

* After Sparrow et al. ${ }^{10}$

\section{Verification of Chamber Mass Transfer and Stability Characteristics}

To verify the applicability of the mass transfer theory for the stable helical flow and to detect the onset of unstable flow, experiments were done on a model chamber employing an electrochemical-mass-transfer technique. The model chamber had a slightly larger shell I.D. (1/2 inch) than that of the test chamber $(13 / 32$ inch).

Mass transfer rates to the shaft surface were measured by means of an electrochemical polarographic technique developed by Eisenberg et al. ${ }^{24}$ (and also used for an annular geometry by Ross and Wragg ${ }^{25}$ ). An electrolyte was used that consisted of $0.001 \mathrm{M}$ potassium ferri- and ferrocyanide (as the electroactive species) in $1 \mathrm{M}$ aqueous $\mathrm{NaOH}$.

Frgures 15A and 15B give typical mass transfer data shown as limiting currents for the polarographic experiments as a function of flow rates, rotation speeds, and viscosity. $\dagger_{\dagger}$

$\dagger \dagger$ Viscosity was adjusted with a cellulosic polymer (Natrosol@-Hercules, Inc.). 
On theoretical grounds, it can be anticipated that the plateau currents and, consequently, the mass transfer coefficients are relatively independent of rotation speed for a given flow rate, at least up to a certain critical speed. At this speed, which is presumed to represent the onset of instability and Taylor vortices, the mass transfer coefficient begins to increase sharply.

Two pieces of information are extracted from such plots: (1) the mass transfer coefficient as a function of axial flow rate for rotation below the critical speed, and (2) the critical rotation speed as a function of axial flow rate.

Reduction of the data to the dimensionless form indicated in FIGURE 15B by the equation

$$
\overline{S h}=\frac{i}{2 \pi R_{1} L F} \frac{\left(R_{2}-R_{1}\right)}{C_{o} D}
$$

(where $\mathrm{i}=$ current, $\mathrm{F}=$ Faraday's constant, $\mathrm{C}_{6}=$ concentration of ferricyanide, $\mathrm{L}=$ length of shaft) requires a knowledge of the effective diffusion coefficient $\mathrm{D}$ for the electroactive current-limiting species $\mathrm{Fe}(\mathrm{CN})_{6}{ }^{-3}$ in the electrolyte solution. For the $1 \mathrm{c} p$ aqueous solution, the value reported by Eisenberg et al. ${ }^{24}$ was used at $23^{\circ} \mathrm{C}, \mathrm{D}=5.11 \times 10^{-6} \frac{\mathrm{cm}^{2}}{\mathrm{sec}}$; for the $3 \mathrm{c} \mathrm{p}$ solution a value of $2.92 \times 10^{-6} \frac{\mathrm{cm}^{2}}{\mathrm{sec}}$ was used to bring the data into coincidence.

FIGURE 15B gives a comparison of the corresponding values of mean Sherwood number for the whole shaft vs. the Peclet number, together with the theoretical relation of Equation 10 (Appendix). Also shown are data for zero axial flow, together with the theoretical estimate, Equation 3.

The data correspond to shaft rotation rates midway between zero and the critical rotation speed.

The agreement of the data with the convection theory of Equation 10 is considered satisfactory for $\mathrm{Pe}>0$ and tends to indicate the absence of severe hydrodynamic end effects. On the other hand, the data for zero axial flow, $\mathbf{P e}=0$, lie far above the pure diffusion asymptote of Equation 11, which can probably be attributed to natural convection or unsteady-state diffusion effects.

The sharp breaks in Figure 15A represent the onset of Taylor vortices in the test chamber. According to the above stability theory, the relation between $\mathrm{Ta}_{c}$ (or $\mathrm{N}_{1} / \nu$ ) and $\operatorname{Re}$ ( or $\mathrm{Q} / \nu$ ) should be independent of the viscosity of the particular Newtonian fluid used. FIGURE 16 summarizes the data for the solutions with viscosities of $1 \mathrm{c} \mathrm{p}$ and $3 \mathrm{c} \mathrm{p}$. There is in the data evident scatter, which is thought to be due in large part to entry effects in the chamber. $\$ \neq$

There is no theory available for the wide gap used here, but the thin gap result of Equation 5 was modified by taking $\left(\mathrm{Ta}_{\mathrm{c}}\right)_{0}$ to be equal to the value 8,250 from TABLE 6 , rather than its thin-gap value 1708 . This modification is shown as the solid curve in Figure 16. Within the precision of the data, there appears to be agreement with our modified thin-gap theory for the Reynolds numbers up to about 60 . This value of $\mathrm{Re}$ may correspond to the onset of higher order instability and the "wavy-vortex" regime predicted for $\operatorname{Re}>75$ by theory (Chandrasekhar), ${ }^{\circ 0}$ but it may also involve hydrodynamic entry effects in the present device. 


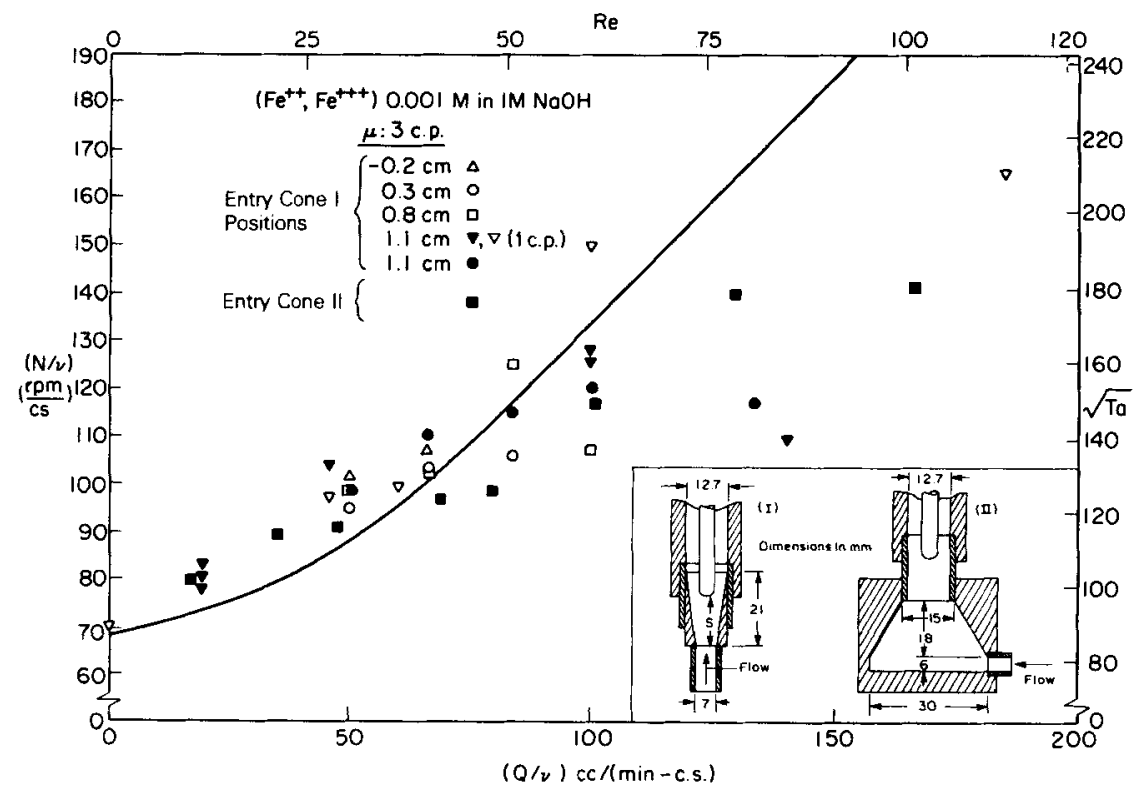

Figure 16. Shaft rotation speed (N) where onset of Taylor-vortex regime commences as a function of flow through the chamber (Q). Solid line is from the modified thin gap theory given in text.

These polarographic data give some confidence in our modified thin-gap theory, Equation 5, for the prediction of the critical rotation speed for blood flowing in the test chamber. Using a value of $3.5 \mathrm{cs}$ for the kinematic viscosity of blood, the critical rotation speeds were calculated from Equation 5 and plotted as a dashed line in FIGURE 14.

Thus, in the stable laminar-helical flow regime, the blood flow rates between 50 and $800 \mathrm{ml} / \mathrm{min}$ and shaft rotation rates between 0 and $1000 \mathrm{rpm}$, it is

\section{TABLE 7}

Summary of Shear Rates Used in Platelet-Adhesion and Related Studies

\begin{tabular}{|c|c|c|}
\hline $\begin{array}{l}\text { Flow } \\
\text { Geometry }\end{array}$ & Investigators & $\begin{array}{l}\text { * Approx. Shear } \\
\text { Rate Range, } \\
\text { Sec }^{-1}\end{array}$ \\
\hline Stagnation point & Nyilas et al..$^{20}$ & $0-25$ \\
\hline $\begin{array}{l}\text { Annular (Couette) } \\
\text { rotational }\end{array}$ & Feuerstein et al. ${ }^{12}$ & $10-20$ \\
\hline Tube (Poiseuille) & Grabowski, et al..$^{27}$ & $10-100$ \\
\hline $\begin{array}{l}\text { Annular axial } \\
\text { (Poiseuille) }\end{array}$ & Turitto and Baumgartner ${ }^{2 s}$ & $2-840$ \\
\hline Rotating disc & Butruille, et al..$^{29}$ & $0-1565$ \\
\hline
\end{tabular}

* As reported in the articles cited. 

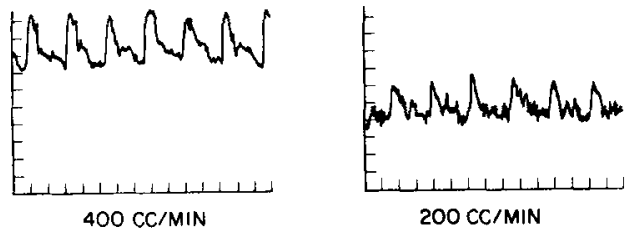

Figure 17. Pulsatile blood flow in ex vivo test chamber when connected to an A-V shunt at mean flows of 200 and $400 \mathrm{cc} / \mathrm{min}$. Time marks on abscissa are at one-second intervals.

possible to attain a range of shear rates of $40-600 \mathrm{sec}^{-1}$ on the shaft surface. This compares well with the shear rates employed in several other platelet adhesion studies, summarized in TABLE 7, and are comparable in range to those found in the larger vessels of the human vascular system.

To assess the effects of pulsatile flow on hydrodynamics and mass transfer, some polarographic studies were undertaken with fluctuating flow $( \pm 15 \%)$ to simulate the flow pattern found in the A-V shunt (FIgURE 17).

It appeared that pulsations of this magnitude do not have an appreciable influence on mean mass transfer rates nor on critical rotation speeds for transition to the Taylor-Vortex regime.

\section{SUMMARY AND CONCLUSIONS}

The flexibility of this test system allows for many different conditions and arrangements to be explored in the testing of biomaterials. The variables include flow rate, shaft rotation speed, sequential order and duration of test, single or parallel sample testing, and systemic anticoagulants.

Up to four test chambers can be run simultaneously. The major constraint on the number of parallel chambers is the blood flow available. Blood flow rates through the shunt without any chambers attached are on the order 800 $\mathrm{ml}$ to 1.3 liters/minute. When the test apparatus is connected, the available blood flow often decreases somewhat because of the flow resistance imposed on the system, so that the flow to the individual chambers is limited by the total shunt output. Four to five chambers in parallel would seem to be the most that can be run at one time.

\section{Flow Conditions}

In the choice of flow conditions for evaluating the different materials, there are some constraints on the flow rate that can be used in these parallel tests. If flow is reduced below $50 \mathrm{ml} / \mathrm{min}$ per chamber, there is a very high likelihood of getting a very rapid thrombus buildup to an extent that the chamber becomes

TABLE 8

Values of Constants a $(k) *$

\begin{tabular}{clllll}
\hline $\begin{array}{l}n=1 / \mathrm{k} \\
\mathrm{a}(\mathrm{k})\end{array}$ & 0.2 & 0.3 & 0.4 & 0.5 & 0.6 \\
& 1.427 & 1.359 & 1.319 & 1.293 & 1.274 \\
\hline
\end{tabular}

* After Lundberg et al. ${ }^{17}$ 
occluded during a normal test period of about one hour. Because of the limitations on total flow available from the shunt, it is unlikely that one could use above $250 \mathrm{ml} / \mathrm{min}$ per chamber if more than two chambers were used in a test.

Within the range of flow rates through the chamber of $50-200 \mathrm{ml} / \mathrm{min}$, the maximum variation in shear rate that can be achieved within the laminar-flow regime is roughly a factor of three and is within the range of shear rates found in the normal vascular system. Although the shear rates in this regime may not be high enough to evaluate embolization, at speeds on the order of 800$1000 \mathrm{rpm}$ the device does achieve the Taylor-vortex regime with concomitant high shear stresses.

\section{Duration of Test}

Our measurements of rates thrombus formation with time have indicated that thrombus accumulation is more or less linear with time, at least for the first 30-45 minutes. In some tests the formation rate began to decrease or to level off at about one hour, and in the tests that were conducted for longer periods of time there was a definite indication that thrombus formation had begun to level off completely. As a matter of practical importance, the ultimate deposition thickness may be a more important parameter than the initial rate of thrombus formation.

Based solely on the normal turnover of platelets and fibrinogen, there are limitations on the length of these chronic tests. Since the turnover time of these blood elements is on the order of four days, the label washes out of the system, and the radioactive detection system becomes less sensitive with time. A more practical procedure is to discontinue the test when, after a few days, the amount of circulating labeled platelets has decreased appreciably.

\section{REFERENCES}

1. Murphy, E. A., H. C. Rowsell, H. G. Downie, G. A. Robinson \& J. F. MusTARD. 1962. Encrustation and atherosclerosis: The analogy between early in-vivo lesions and deposits which occur in extracorporeal circulations. J. Can. Med. Assoc. 87: 259-274.

2. Downie, H. G., E. A. Murphy, H. C. Rowsell \& J. F. Mustard. 1963. Extracorporeal circulation: A device for the quantitative study of thrombus formation in flowing blood. Circulation Res. 12: 441-448.

3. Leonard, E. F. \& D. S. Litwak. 1972. 5th Ann. Contractors Conf. Artificial Kidney Program. DHEW Pub. NIH 72-248: 97.

4. Rembaum, A., S. P. S. Yen, M. Ingram, I. F. Newton, W. G. Frasher \& B. H. Barbour. 1973. Platelet adhesion to heparin-bonded and heparin-free surfaces. Biomat. Med. Div. Art. Org. 1: 99-119.

5. Dutton, R. C., R. E. Baier, R. L. Dedrick \& R. L. Bowman. 1968. Initial thrombus formation on foreign surfaces. Trans. Am. Soc. Artif. Intern. Organs 14: 57.

6. Petschex, H., D. Adams \& A. R. Kantrowitz. 1968. Stagnation flow thrombus formation. Trans. Am. Soc. Artif. Intern. Organs 14: 256.

7. Frasher, W. G. 1967. Blood sampling by a chronic artificial external arteriovenous shunt in dogs. J. Appl. Physiol. 27: 348.

8. Harker, L. A. 1974. Hemostatis Manual. 2nd edit. F. A. Davis. Pa.

9. Mustard, J. F., R. L. Kinlough-Rathbone \& M. A. Packam. 1974. Throm- 
bosis: Pathogenesis and clinical trials. Thromb. Diath. Haemorrh. (Suppl.) 59.

10. Thomas, D. P. 1972. The role of platelets in arterial and venous thrombosis, Adv. Exp. Med. Biol. 34: 23.

11. Baumgartner, H. R. 1973. The role of blood flow in platelet adhesion, fibrin deposition and formation of mural thrombi: Microvascular Res. 5: 167.

12. Feuerstein, I. A., J. M. Brophy \& J. L. Brash. 1975. Platelet transport and adhesion to reconstituted collagen and artificial surfaces. Trans. Am. Soc. Artif. Intern. Oragns 21: 427.

13. Olson, P. S., U. LuUngQvist \& S. E. Bergentz. 1974. Analysis of platelet, red cell and fibrin content in experimental arterial and venous thrombi. Thromb. Res. 5: 1.

14. Olson, P. S., C. Busch \& O. LINDQuist. 1974. Thrombus formation in the arterial and venous circulation in thrombocytopenic dogs. Europ. Surg. Res. 6: $54-64$.

15. Aster, R. H. \& J. H. JANDL. 1964. Platelet sequentiation in man. I. Methods. J. Clin. Invest. 43: 843.

16. Foster, E. D. \& A. R. C. Dobell. 1971. Evaluation of rigid prosthetic rings as in-vivo intravascular thrombogenic models. J. Surg. Res. 11: 550.

17. Lundberg, R. E., W. C. Reynolds \& W. M. Ways. 1963. NASA Report: NASA-TND-1972.

18. Goldsmith, L. H. 1972. The flow of model particles and blood cells and its relation to thrombogenesis. Progress in Hemostasis and Thrombosis. Vol. 1. E. Spaet, Ed. : 97. Grune and Stratton. New York, N.Y.

19. Sparrow, E. M., W. D. Munro \& V. K. Jonsson. 1964. Instability of the flow between rotating cylinders: The wide-gap problem. J. Fluid. Mech. 20: 35.

20. Chandrasekhar, S. 1961. Hydrodynamic and hydromagnetic stability. Oxford Clarendon Press. Oxford, England.

21. DATTA, S. K. 1965. Stability of spiral flow between concentric circular cylinders at low axial number. J. Fluid Mech. 21: 635.

22. Krueger, E. R. \& R. C. Prima. 1964. Stability of viscous fluid between rotating cylinders with axial flow. J. Fluid Mech. 19: 528.

23. Hughes, T. H. \& W. H. ReID. 1968. The stability of spiral flow between rotating cylinders. Proc. R. Soc. Lond. [Biol.] A263: 8.

24. Eisenberg, M., C. W. Tobias, C. R. Wilke. 1955. Mass transfer at rotating cylinders. Chem. Eng. Prog. Symp. Ser. 51(16): 1.

25. Ross, K. \& A. WRAGG. 1965. Electrochemical mass transfer studies in annuli. Electrochem. Acta 10: 1093.

26. Nyilas, E., W. A. Morton, D. M. Lederman, T. H. Chiu. \& R. D. Cumming. 1975. Interdependence of hemodynamic and surface parameters in thrombosis. Trans. ASAIO. 21: 55 .

27. Grabowski, E. F., L. I. Friedman \& E. F. Leonard. 1972, Effects of shear rate on diffusion and adhesion of blood platelets to a foreign surface. Ind. Eng. Chem. Fund. 11: 224.

28. Turritto, V. T. \& H. R. Baumgartner. 1975. Platelet deposition on subendothelium exposed to flowing blood: mathematical analysis of physical parameters. Trans. Am. Soc. Artif. Intern. Organs 21: 593-600.

29. Butruille, Y. A., E. F. Leonard \& D. S. Litwak. 1975. Platelet-platelet interaction and non-adhesive encounters on biomaterials. Trans. Am. Soc. Artif. Intern. Organs 21: 609.

\section{APpendix}

For a Newtonian fluid the axial (z) velocity profile in an annulus is given by the following equation: 